\title{
Treatment of Corneal Alkali Burn with Chestnut Honey, Royal Jelly, and Chestnut Honey-Royal Jelly Mixture
}

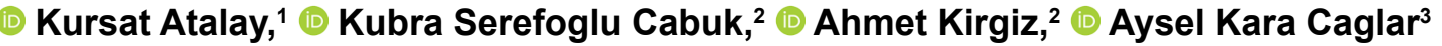 \\ 1Department of Ophthalmology, Istanbul University of Health Sciences, Bagcilar Training and Research Hospital, Istanbul, Turkey \\ ${ }^{2}$ Department of Ophthalmology, Istanbul University of Health Sciences, Beyoglu Resat Belger Eye Training and Research Hospital, \\ Istanbul, Turkey \\ ${ }^{3}$ Department of Pathology, Istanbul University of Health Sciences, Bagcilar Training and Research Hospital, Istanbul, Turkey
}

\begin{abstract}
Objectives: The alkaline burn of the cornea usually results in a decreased vision with opacification. In this study, we investigated the potential role of endemic chestnut honey $(\mathrm{CH})$ and royal jelly on corneal healing after an alkaline burn. Methods: We created an alkaline burn on the center of the corneas of four groups of Wistar rats by applying round filter paper soaked with I $\mathrm{N} \mathrm{NaOH}$ for 30 seconds. The animals were treated with $\mathrm{RJ}, \mathrm{CH}, \mathrm{RJ}-\mathrm{CH}$ combination and $\mathrm{Na}$ Hyaluronate $(\mathrm{Na}-\mathrm{HA})$ eye drops. We performed a serial evaluation with anterior segment photography on the first, 7 th, and 14th days of the experiment. Pathologic examination conducted with hematoxylin and eosin stains and immunostaining for SMA and $\alpha 4 \beta$ I integrin. We evaluated the corneal healing process with a scoring system, which was estimating the degree of corneal edema, the size of the corneal ulcer, and limbal hyperemia.

Results: There was no statistically significant difference between groups on the first, $7^{\text {th }}$, and $14^{\text {th }}$ days concerning the healing scores $(p=0.88, p=0.06, p=0.80$, respectively). However, there were significantly better scores in the repeated measures of $\mathrm{CH}(p=0.012)$ and $\mathrm{RJ}-\mathrm{CH}(p=0.00)$ groups. The RJ group and $\mathrm{Na}-\mathrm{HA}$ group did not show a significant difference in repeated measures $(p=0.19$ and $p=0.10$, respectively). The $\alpha 4 \beta 1$ integrin levels on immunostaining showed a significant difference among groups on the $14^{\text {th }}$ day $(p=0.002)$.

Conclusion: We found better corneal healing after treatment with the $\mathrm{RJ}-\mathrm{CH}$ containing eye drops concerning corneal healing sore and $\alpha 4 \beta I$ integrin staining.

Keywords: Cornea, corneal alkaline burn, chestnut honey, royal jelly, smooth muscle antigen, $\alpha 4 \beta I$ integrin.
\end{abstract}

\section{Introduction}

The corneal alkaline burn is still a significant cause of visual disruption. The proper healing of cornea after an alkaline injury is vital for the restoration of vision and ocular comfort (I). An inflammatory reaction begins shortly after an alkaline insult to the cornea. The release of tissue remodeling enzymes, such as matrix metalloproteinases (MMPs), and proinflammatory cytokines, such as tumor necrosis factor-alpha (TNF- $\alpha$ ), were observed in the early periods of inflammation
$(2,3)$. The function and structure of epithelial and stromal cells change so that they secrete several intracytoplasmic and cell membrane proteins, including smooth muscle antigen (SMA) and integrins, to interact with the environment, especially the basement membrane (BM) (4). The balance in tissue response against alkaline damage results in an excellent transparent three-dimensional integrity.

Several treatment strategies, including early irrigation with buffered solutions and vigorous artificial tear drop in-

Address for correspondence: Kursat Atalay, MD. Istanbul Saglik Bilimleri Universitesi, Bagcilar Egitim ve Arastirma Hastanesi, Goz Hastaliklari Anabilim Dali, Istanbul, Turkey Phone: +90 5052697152 E-mail: drkursatalay@gmail.com

Submitted Date: July 02, 2019 Accepted Date: August 25, 2019 Available Online Date: December 27, 2019

${ }^{\circledR}$ Copyright 2019 by Beyoglu Eye Training and Research Hospital - Available online at www.beyoglueye.com OPEN ACCESS This work is licensed under a Creative Commons Attribution-NonCommercial 4.0 International License. 
stallation, used to limit the tissue degradation with some degree of success $(5,6)$. The artificial tear drops containing sodium hyaluronate $(\mathrm{Na}-\mathrm{HA})$ help corneal reepithelization with the restoration of $\mathrm{pH}$ stability of the ocular surface and improve patient comfort $(7,8)$. Despite shown beneficial effects of the Na-HA on corneal healing, better treatment options are required to restore the corneal structure.

The ophthalmologic usage of different types of honey and royal jelly $(R J)$ was tried in the treatment of several experimental animal models of ocular surface diseases, including corneal burns, with variable degrees of improvement (9-14). The chestnut honey $(\mathrm{CH})$ is endemic in Turkey and is used widely as complementary medicine for several conditions. However, a gap exists in current knowledge about the potential effects of $\mathrm{RJ}, \mathrm{CH}$, and $\mathrm{RJ}-\mathrm{CH}$ combination on the corneal healing process after an alkaline insult. In this study, we investigated the potential role of topical $\mathrm{RJ}, \mathrm{CH}$, and RJ$\mathrm{CH}$ combination drops for the treatment of experimentally induced rat model of corneal alkaline burn.

\section{Methods}

\section{General Information}

The Animal Experiments Local Ethics Committee of Bagcilar Teaching and Research Hospital (HADYEK project number: 2017-10) approved this experiment. This study was conducted between II-03-20I7 and II-I7-20I7 by the principles of the Declaration of Helsinki and carried out by considering animal rights. Our study included four groups of Wistar rats. Each group consisted of six animals. We created an alkaline burn on the center of the corneas by applying a $3.5 \mathrm{~mm}$ in diameter round filter paper soaked with I N $\mathrm{NaOH}$ for 30 seconds. We irrigated the ocular surface of each eye with $10 \mathrm{ml}$ of sterile $0.09 \% \mathrm{NaCl}$ as a first-line standard treatment. A gamma irradiation process with $25 \mathrm{kGy}$ doses was done to sterilize $\mathrm{RJ}$ and $\mathrm{CH}$. We arranged $\mathrm{I} \%$ eye drop solutions for the $\mathrm{RJ}$ and the $\mathrm{CH}$ groups. We prepared a solution containing $0.05 \% \mathrm{RJ}$ and $0.05 \% \mathrm{CH}$ for the $\mathrm{RJ}-\mathrm{CH}$ treatment group. The animals were treated four times a day only with $\mathrm{RJ}, \mathrm{CH}, \mathrm{RJ}-\mathrm{CH}$ combination, and $0.15 \% \mathrm{Na}-\mathrm{HA}$ (Eyestil TM, SIFI S.p.A.) eye drop.

\section{Interpretation of Inflammation and Corneal Epithelium Healing}

The description of the measurement of inflammation and corneal epithelium healing process is present in previous studies with detail $(15,16)$. We have used a slightly modified approach for the evaluation of inflammation and corneal healing. Serial slit lamp biomicroscopic photographs were taken at first, $7^{\text {th }}$ and $14^{\text {th }}$ days of examination. The direct images were gained at first, later for taking a second pic- ture the cornea stained with one drop of $0.1 \%$ fluorescein sodium solution to measure the size of the epithelial defect. We calculated the corneal healing score with the use of three markers. The first marker was ciliary hyperemia (absent $=0$; present but less than I $\mathrm{mm}=\mathrm{I}$; present between I and $2 \mathrm{~mm}=2$; present and more than $2 \mathrm{~mm}=3$ ). The second marker was central corneal edema (absent $=0$; present with visible iris details $=\mathrm{I}$; present without visible iris details $=2$; present without visible pupil=3); peripheral corneal edema (absent $=0$; present with visible iris details $=\mathrm{I}$; present without visible iris details $=2$; present with no visible iris $=3$ ). The third marker was the corneal epithelial staining (no staining $=0$; slight punctate staining $=0.5$; diffuse punctate staining $=1$; diffuse staining covering less than one-third of the cornea $=2$; diffuse staining covering more than one-third of the cornea $=3$; and staining covering more than two-thirds of the cornea=4). A total score for each examination date was used for the overall physiologic healing response.

\section{Evaluation of Histological Sections}

A single pathologist (AC) handled the histopathologic examination of specimens. After enucleation and removal of corneas, the samples fixed in a $10 \%$ formaldehyde solution of $20 \mathrm{ml}$ for 24 hours, samples from each group were macroscopically taken into cassettes and then dehydrated in a tissue tracking device by being passed through alcohol, acetone, xylene, and paraffin phases. The paraffin blocking was conducted thereafter. The hematoxylin and eosin (HE) staining was done to each block after taking cuts of $4 \mu \mathrm{m}$. The covering solution was dripped on the painted lames, and they were closed with lamellas. After the necessary examination with $\mathrm{HE}$, an immunohistochemical examination for SMA and $\alpha 4 \beta$ I integrin were applied to each block with $4 \mathrm{~nm}$ sections. In the evaluation of the SMA, the cells that stained from 100 cells in the stroma were counted at $\mathrm{X} 400$ magnification. The value is given in percentage. The cells that were painted from 100 cells in the stroma at $X 400$ magnification were counted in the evaluation of $\alpha 4 \beta I$ integrin. The amount is given in percentage. We used a light microscope (BX5ITF TM, Olympus, Tokyo, Japan) to evaluate tissue sections.

\section{Statistical Methods}

We used open-source software, namely PSPP (a GNU project), for statistics. We expressed all continuous data as a mean \pm standard deviation where applicable. Categorical variables were analyzed with the chi-square test (X2). Repeated measures were analyzed with the Friedman test. The MannWhitney $U$ test was used for comparing two groups. The Kruskal-Wallis test was used to test more than two groups. The values of less than 0.05 were considered statistically significant for the measured $P$-values. 


\section{Results}

\section{Corneal Healing Scores}

We measured the corneal healing scores on the first, $7^{\text {th }}$, and $14^{\text {th }}$ days after the corneal alkaline burn induction. Figure I shows the fluorescein staining patterns of groups. We observed a decrease in total healing scores in all groups emphasizing a stable healing activity. Table I shows the corneal healing scores of all groups. There was no statistically significant difference between groups on the first, $7^{\text {th }}$, and $14^{\text {th }}$ days concerning the corneal healing scores $(p=0.88, p=0.06$, $p=0.80$, respectively). However, there were significantly better scores in repeated measures of $\mathrm{CH}(\mathrm{P}=0.012)$ and $\mathrm{RJ}-\mathrm{CH}$ $(p=0.000) . R J$ and $\mathrm{Na}-\mathrm{HA}$ did not show a significant difference in repeated measures ( $p=0.19$ and $p=0.10$, respectively).

\section{Histopathologic Examination Results}

The HE staining of all groups shows complete reepithelization without any sign of inflammation. Anti-SMA immunohistochemical staining at $14^{\text {th }}$ day showed no staining with SMA antigen in any of the groups ( $0 \%)$. However, there was a significant difference between the groups for the $\alpha 4 \beta I$ integrin staining of stromal cells on the $14^{\text {th }}$ day $(p=0.002)$ (Table 2 ), which was due to the significantly different $\alpha 4 \beta I$ integrin staining levels between the $\mathrm{RJ}$ and the $\mathrm{CH}$ groups $(p=0.019)$ and the $\mathrm{RJ}$ and the $\mathrm{RJ}-\mathrm{CH}$ groups $(p=0.003)$. When the $\mathrm{RJ}$ and the $\mathrm{Na}-\mathrm{HA}$ groups compared for the $\alpha 4 \beta \mathrm{I}$ integrin staining, no significant difference was analyzed $(p=0.335)$. The staining for the $\alpha 4 \beta$ I integrin was significantly different between the $\mathrm{CH}$ and the $\mathrm{RJ}-\mathrm{CH}$ groups $(p=0.027)$. When we compared the $\mathrm{CH}$ and the $\mathrm{Na}-\mathrm{HA}$ groups, we found no significant difference for the $\alpha 4 \beta \mid$ integrin staining $(p=0.18)$.
Table I. Corneal healing score

\begin{tabular}{lccccc} 
& $\mathbf{R J}$ & $\mathbf{C H}^{*}$ & $\mathbf{R J}-\mathbf{C H}^{*}$ & $\mathbf{N a H A} *$ & $\mathbf{P I}$ \\
\hline CHS I $^{\text {st }}$ day & $5.16 \pm 0.40$ & $5.33 \pm 0.5 \mathrm{I}$ & $5.66 \pm 1.03$ & $5.25 \pm 0.95$ & 0.88 \\
CHS 7 $^{\text {th }}$ day & $3.66 \pm 2.02$ & $2.50 \pm 0.63$ & $3.58 \pm 0.73$ & $2.50 \pm 0.0$ & 0.06 \\
CHS I4 $^{\text {th }}$ day & $2.12 \pm 1.10$ & $2.50 \pm 0.6 \mathrm{I}$ & $2.66 \pm 0.68$ & $2.50 \pm 0.70$ & 0.80 \\
P2* & 0.19 & 0.012 & 0.00 & 0.11 & \\
\hline
\end{tabular}

*PI Stands for Kruskal-Wallis test significance level; P2 stands for the Friedman test significance level; $\mathrm{CHS}$ stands for the corneal healing score; $\mathrm{RJ}$ : Royal Jelly; $\mathrm{CH}$ : Chestnut Honey; RJ-CH: Royal Jelly-Chestnut Honey; NaHA: Sodium Hyaluronate.

The $\mathrm{RJ}-\mathrm{CH}$ and the $\mathrm{Na}-\mathrm{HA}$ groups were significantly different in staining for the $\alpha 4 \beta I$ integrin $(p=0.008)$. Figure 2 displays some of the pathologic sections of the NaHA group and $\mathrm{RJ}-\mathrm{CH}$ group for different staining techniques.

\section{Discussion}

A transparent cornea, which is necessary for a good vision, can be harmed with an alkaline burn. This type of injury has been tried to treat with several medications with limited success. Honey and RJ are two remedies successfully used for some ocular diseases. Here, we investigated the potential role of $\mathrm{CH}, \mathrm{RJ}$ and $\mathrm{CH}-\mathrm{RJ}$ combination for the treatment of alkaline burn of the cornea and found better treatment results in $\mathrm{CH}-\mathrm{RJ}$ treated group concerning improved corneal healings scores in repeated measures and $\alpha 4 \beta I$ integrin staining characteristics.

Corneal epithelial healing is a complex process with the propagation of corneal epithelial cell in three-dimensional $x, y$, and $z$-axis. The failure of this healing process for any reason results in an ulcerated corneal surface. The inflam-
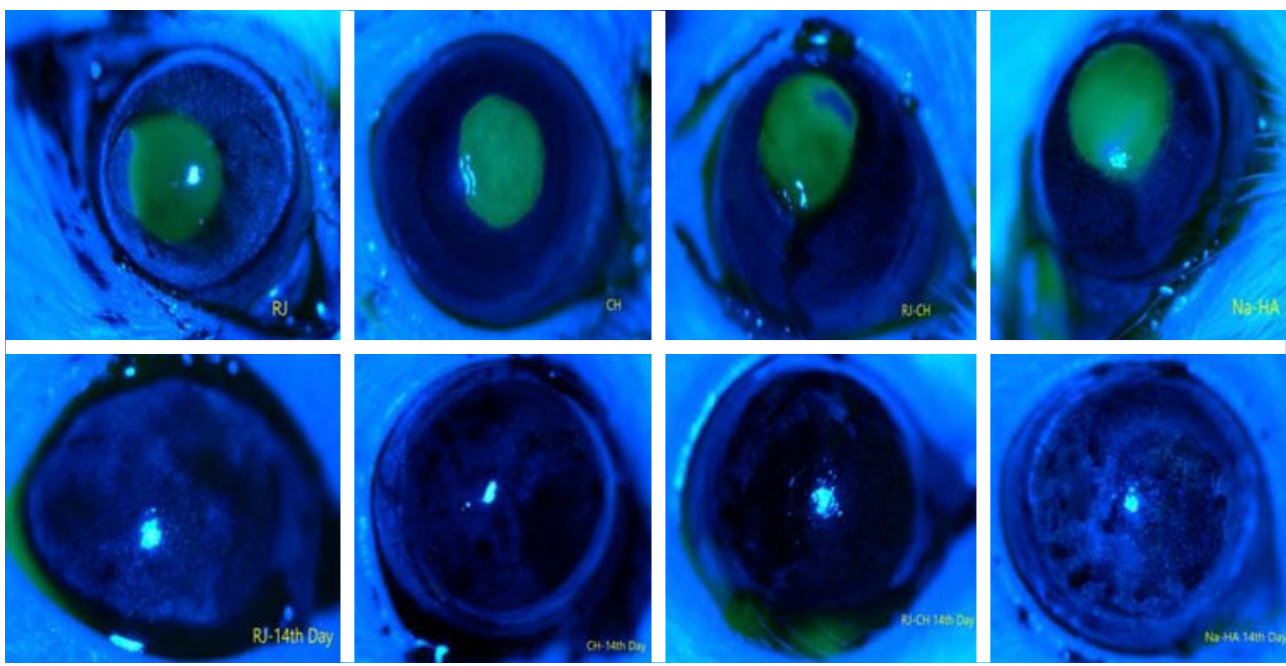

Figure I. The frames on the upper part of the figure show the fluorescein staining of each group on the first day. The lower part of the figure contains the pictures taken on the $14^{\text {th }}$ day $(\mathrm{RJ}=\mathrm{Royal}$ Jelly, $\mathrm{CH}=$ Chestnut Honey, $\mathrm{RJ}-\mathrm{CH}=$ Royal Jelly-Chestnut Honey, NaHA= Sodium Hyaluronate). 
Table 2. The number of $\alpha 4 \beta$ I staining cells

\begin{tabular}{cccccc} 
& \multicolumn{4}{c}{ Groups } & P \\
\cline { 2 - 5 } & RJ & CH & RJ-CH & Na-HA \\
\hline Number of $\alpha 4 \beta$ I staining cells & $96.66 \pm 5.16$ & $73.33 \pm 16.02$ & $55.00 \pm 8.36$ & $88.75 \pm 14.36$ & 0.002 \\
\hline
\end{tabular}

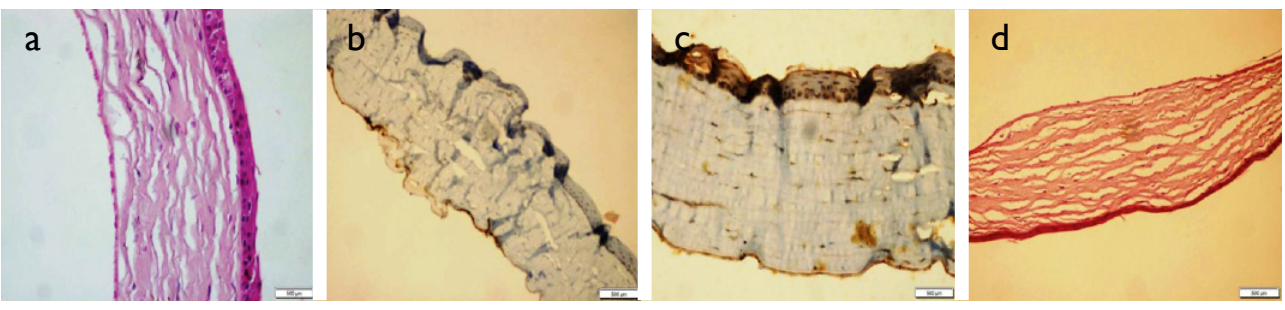

Figure 2. Some of the pathologic sections of the Sodium Hyaluronate ( $\mathrm{NaHA})$ group and Royal Jelly $(\mathrm{RJ}-\mathrm{CH})$ group for different staining techniques. (a) NaHA group, full epithelialization in the section, moderate edema is observed, and no active and chronic inflammatory cell infiltration is observed, $\mathrm{HE}$, X400; (b) RJ-CH group, SMA immunoreactive stromal cell in cross-section was not observed, SMA, $\mathrm{X} 200$; (c) $\mathrm{RJ}-\mathrm{CH}$ group, Half of the stromal cells in the section are immunoreactive with $\alpha 4 \beta \mathrm{I}$ integrin 4, X400; (d) $\mathrm{RJ}-\mathrm{CH}$ group, full epithelization in the section, moderate edema is observed, and no active and chronic inflammatory cell infiltration is observed, $\mathrm{HE}, \mathrm{X} 200$.

mation of the cornea is one of the critical causes of corneal ulceration (17). Also, the inflammatory cells in the wound area increase paracrine secretion of oxidizing agents, inflammatory cytokines, and tissue remodeling enzymes (18). There are many studies on the protective effects of different honey varieties and RJ against excessive inflammatory responses and oxidative stress (9, 19-2I). In an experiment that used the rabbit corneal alkali burn model, Tualang honey displayed reduced conjunctival hyperemia, reduced corneal edema and reduced neutrophilic infiltration, which was not significantly different from the treatment with prednisolone acetate one percent, ciprofloxacin 0.3 percent and oral ascorbic acid (20). In another experiment, Uwaydat et al. showed a faster epithelisation and decreased corneal expression of vascular endothelial growth factor (VEGF), transforming growth factor-beta (TGF $\beta$ ), interferon-gamma, interleukin 12 , and tumour necrosis factoralpha (TNF- $\alpha$ ) in a rat model of corneal abrasion and P. aeruginosa toxin immune-mediated keratitis treated with soybean/wildflower honey (14). The keratocytes and polymorphonuclear cells secrete MMPs during the early phases of wound healing $(2,22,23)$. The inhibition of MMPs shows some beneficial effects on the healing of corneal ulceration $(24,25)$. Paterson et al. reported that the tissue inhibitors of MMPs were equal to the synthetic inhibitor of MMPs at ameliorating corneal ulcers in a rabbit model of corneal alkali burn. Majtan et al. examined the major royal jelly protein one (MRJPI) that is an essential active compound of RJ and acacia honey on the expression of MMP mRNA from human keratinocytes and found an increased MMP mRNA expression in acacia honey group but no induction in production of mRNA of MMP in (MRJPI) group (26). In our study, corneal ulceration improved on the $14^{\text {th }}$ day of treatment in all groups, suggesting that agents used in all groups were active. In our research, there are clinical findings that support the improvement of cellular propagation in the mixture of $\mathrm{CH}-\mathrm{RJ}$ and $\mathrm{CH}$ on epithelial healing.

Myofibroblasts play an essential role in the closure of the wound by podophilic movements through actin microfilaments that they have during wound healing (27). Corneal haze may arise from myofibroblasts that occur during corneal wound healing because they do not turn into keratocytes, which are specialized fibroblasts $(27,28)$. The emergence of inflammatory responses in tissue supports the activation of myofibroblasts (29). At the end of the normal healing process, myofibroblasts stop the production of SMA (30). They may become scar keratocytes or fade with apoptosis (30). In our study, no SMA positive cells were detected in the stroma after SMA staining to detect the presence of myofibroblasts in tissue. An inflammatory cell response typically seen in the early stages of wound healing is not shown in HE staining of all groups, and the absence of SMA positive cells suggests that the treatments given in all groups effectively control inflammation.

Integrins that are also known as very late activation (VLA) antigen are a group of heterodimeric integral membrane proteins ( $3 \mathrm{I})$. They have several cells to cell and cell to ECM interactions. The corneal keratocytes express $\alpha 4 \beta$ I integrin after an inflammatory response $(32,33)$. The $\alpha 4 \beta$ I integrin binds to fibronectin, which is a critical ECM component. The sources of the fibronectin $(\mathrm{Fn})$ are tissue fi- 
broblasts or hepatocytes. The tissue fibroblasts secrete a subtype of fibronectin called EDA Fn after an injury. Recent reports show a mutual relation between $\alpha 4 \beta I$ integrin and EDA Fn secretion during the healing process (34). Besides, $\alpha 4 \beta I$ integrin is a receptor for soluble vascular cell adhesion molecule-I (VCAM-I) which is induced after secretion of pro-inflammatory cytokines, such as tumor necrosis factor $\alpha$ (TNF- $\alpha$ ) (35). Inhibition of the interaction between $\alpha 4 \beta$ I integrin and soluble VCAM-I blocks the neovascularization $(3,36)$. Both disorganized ECM and neovascularization impair the corneal clarity. The honey exerts different effects in wound healing employing inflammatory cytokine production. That is, some studies relate a pro-inflammatory action, while some studies do not connect with pro-inflammation (14, $37,38)$. On the other, RJ decreases inflammatory response through reduced production of cytokines $(12,39)$. In our study, in RJ (96.66 \pm 5.16$)$ and $\mathrm{Na}-\mathrm{HA}(88.75 \pm 14.36)$ groups, stromal fibroblast $\alpha 4 \beta \mathrm{I}$ integrin staining rates were higher than $\mathrm{CH}(77.33 \pm 16.02)$ and $\mathrm{RJ}-\mathrm{CH}$ groups $(55.00 \pm 8.36)$. We observed a significant difference in the $\alpha 4 \beta I$ integrin staining levels between the groups, and this difference was due to the low level of $\alpha 4 \beta \mathrm{I}$ integrin staining of $\mathrm{RJ}-\mathrm{CH}$ and $\mathrm{CH}$ groups. Also, in the comparison of the $\mathrm{CH}$ group and $\mathrm{RJ}-\mathrm{CH}$ group, a low level of staining was detected in the $\mathrm{RJ}-\mathrm{CH}$ group. According to our study, there was no clinical difference in corneal healing scores in $\mathrm{RJ}, \mathrm{CH}$, and $\mathrm{RJ}-\mathrm{CH}$ groups compared to the NaHA group. However, concerning the amount of $\alpha 4 \beta I$ integrin staining at the cellular level, better corneal healing seems to be present after installation of the $\mathrm{RJ}-\mathrm{CH}$ containing eye drops, which may be due to the synergistic action of both of these materials on immunomodulation and fibroblast interaction with ECM.

\section{Conclusion}

In conclusion, we find better corneal healing after treatment with the $\mathrm{RJ}-\mathrm{CH}$ containing eye drops concerning corneal healing sore and $\alpha 4 \beta I$ integrin staining in an experimental animal model of corneal alkaline injury.

\section{Acknowledgments}

We acknowledge Prof. Dr. Sevgi Kolaylı for gaining chestnut honey and royal jelly.

\section{Disclosures}

Ethics Committee Approval: The Animal Experiments Local Ethics Committee of Bagcilar Teaching and Research Hospital (HADYEK project number: 2017-10).

Peer-review: Externally peer-reviewed.

Conflict of Interest: None declared.

Authorship Contributions: Involved in design and conduct of the study (KSC, KA, AK, AKC); preparation and review of the study $(K A)$; data collection (KA, KSC, AK); and statistical analysis (KA).

\section{References}

I. Lu L, Reinach PS, Kao WW. Corneal epithelial wound healing. Exp Biol Med (Maywood) 200I;226:653-64. [CrossRef]

2. Iwanami H, Ishizaki M, Fukuda $Y$, Takahashi H. Expression of matrix metalloproteinases (MMP)- 12 by myofibroblasts during alkali-burned corneal wound healing. Curr Eye Res 2009;34:20714. [CrossRef]

3. Nakao S, Kuwano T, Ishibashi T, Kuwano M, Ono M. Synergistic effect of TNF-alpha in soluble VCAM-I-induced angiogenesis through alpha 4 integrins. J Immunol 2003; 170):5704-I I.

4. Liu CY, Kao WW. Corneal Epithelial Wound Healing. Prog Mol Biol Transl Sci 2015;134:6I-7I. [CrossRef]

5. Schrage NF, Rihawi R, Frentz M, Reim M. [Acute therapy for eye burns]. [Article in German]. Klin Monbl Augenheilkd 2004;22I:253-6I. [CrossRef]

6. Zhang Y, Lu XY, Hu RJ, Fan FL, Jin XM. Evaluation of artificial tears on cornea epithelium healing. Int J Ophthalmol 2018;11:1096-101.

7. Gomes JA, Amankwah R, Powell-Richards A, Dua HS. Sodium hyaluronate (hyaluronic acid) promotes migration of human corneal epithelial cells in vitro. $\mathrm{Br} J$ Ophthalmol 2004;88:82 I-5.

8. Fallacara A, Vertuani S, Panozzo G, Pecorelli A, Valacchi G, Manfredini S. Novel Artificial Tears Containing Cross-Linked Hyaluronic Acid: An In Vitro Re-Epithelialization Study. Molecules 2017 30;22. [CrossRef]

9. Salehi A, Jabarzare S, Neurmohamadi M, Kheiri S, RafieianKopaei M. A double blind clinical trial on the efficacy of honey drop in vernal keratoconjunctivitis. Evid Based Complement Alternat Med 20 I4;20 I4:287540. [CrossRef]

10. Mansour AM, Zein W, Haddad R, Khoury J. Bullous keratopathy treated with honey. Acta Ophthalmol Scand 2004;82:3 I2-3.

II. Albietz JM, Lenton LM. Standardised antibacterial Manuka honey in the management of persistent post-operative corneal oedema: a case series. Clin Exp Optom 2015;98:464-72.

12. Oztürk F, Kurt E, Cerçi M, Emiroglu L, Inan U, Türker M, et al. The effect of propolis extract in experimental chemical corneal injury. Ophthalmic Res 2000;32:13-8. [CrossRef]

13. Ker-Woon C, Abd Ghafar N, Hui CK, Mohd Yusof YA, Wan Ngah WZ. The effects of acacia honey on in vitro corneal abrasion wound healing model. BMC Cell Biol 2015;16:2. [CrossRef]

14. Uwaydat SI, Jha P, Tytarenko R, Brown H, Wiggins M, Bora $\mathrm{PS}$, et al. The use of topical honey in the treatment of corneal abrasions and endotoxin-induced keratitis in an animal model. Curr Eye Res. 201 I;36:787-96. [CrossRef]

15. Laria C, Alió JL, Ruiz-Moreno JM. Combined non-steroidal therapy in experimental corneal injury. Ophthalmic Res 1997;29:145-53. [CrossRef]

16. Liu X, Lin Z, Zhou T, Zong R, He H, Liu Z, et al. Anti-angiogenic and anti-inflammatory effects of SERPINA3K on corneal injury. PLoS One 2011;6:e167/2. [CrossRef] 
17. Ma DH, Wang SF, Su WY, Tsai RJ. Amniotic membrane graft for the management of scleral melting and corneal perforation in recalcitrant infectious scleral and corneoscleral ulcers. Cornea 2002;21:275-83. [CrossRef]

18. Bian F, Pelegrino FS, Pflugfelder SC, Volpe EA, Li DQ, de Paiva CS. Desiccating Stress-Induced MMP Production and Activity Worsens Wound Healing in Alkali-Burned Corneas. Invest Ophthalmol Vis Sci. 2015;56:4908-18. [CrossRef]

19. Erejuwa OO, Sulaiman SA, Ab Wahab MS. Honey: a novel antioxidant. Molecules 20I2; I7:4400-23. [CrossRef]

20. Bashkaran K, Zunaina E, Bakiah S, Sulaiman SA, Sirajudeen K, Naik V. Anti-inflammatory and antioxidant effects of Tualang honey in alkali injury on the eyes of rabbits: experimental animal study. BMC Complement Altern Med 20 I I; I I:90. [CrossRef]

2I. Tan JJ, Azmi SM, Yong YK, Cheah HL, Lim V, Sandai D, et al. Tualang honey improves human corneal epithelial progenitor cell migration and cellular resistance to oxidative stress in vitro. PLoS One. 2014;9:e96800. [CrossRef]

22. Salo T, Mäkelä M, Kylmäniemi M, Autio-Harmainen H, Larjava $\mathrm{H}$. Expression of matrix metalloproteinase-2 and -9 during early human wound healing. Lab Invest 1994;70:176-82.

23. Ikema K, Matsumoto K, Inomata Y, Komohara Y, Miyajima $S$, Takeya $M$, et al. Induction of matrix metalloproteinases (MMPs) and tissue inhibitors of MMPs correlates with outcome of acute experimental pseudomonal keratitis. Exp Eye Res 2006;83:1396-404. [CrossRef]

24. Brooks DE, Ollivier FJ. Matrix metalloproteinase inhibition in corneal ulceration. Vet Clin North Am Small Anim Pract 2004;34:6 I I-22. [CrossRef]

25. Paterson CA, Wells JG, Koklitis PA, Higgs GA, Docherty AJ. Recombinant tissue inhibitor of metalloproteinases type I suppresses alkali-burn-induced corneal ulceration in rabbits. Invest Ophthalmol Vis Sci 1994;35:677-84.

26. Majtan J, Kumar P, Majtan T, Walls AF, Klaudiny J. Effect of honey and its major royal jelly protein I on cytokine and MMP9 mRNA transcripts in human keratinocytes. Exp Dermatol 2010;19:e73-9. [CrossRef]

27. Netto MV, Mohan RR, Sinha S, Sharma A, Dupps W, Wilson SE. Stromal haze, myofibroblasts, and surface irregularity after PRK. Exp Eye Res 2006;82:788-97. [CrossRef]

28. Karamichos DI, Guo XQ, Hutcheon AE, Zieske JD. Human corneal fibrosis: an in vitro model. Invest Ophthalmol Vis Sci 2010;5।:1382-8. [CrossRef]

29. Navas A, Magaña-Guerrero FS, Domínguez-López A, ChávezGarcía C, Partido G, Graue-Hernández EO, et al. Anti-Inflammatory and Anti-Fibrotic Effects of Human Amniotic Membrane Mesenchymal Stem Cells and Their Potential in Corneal Repair. Stem Cells Transl Med 2018;7:906-17. [CrossRef]

30. Ljubimov AV, Saghizadeh M. Progress in corneal wound healing. Prog Retin Eye Res 2015;49:17-45. [CrossRef]

31. Humphries MJ. Integrin structure. Biochem Soc Trans 2000;28:3I I-39. [CrossRef]

32. Vorkauf W, Vorkauf M, Nölle B, Duncker G. Adhesion molecules in normal and pathological corneas. An immunohistochemical study using monoclonal antibodies. Graefes Arch Clin Exp Ophthalmol 1995;233:209-19. [CrossRef]

33. Lauweryns B, van den Oord JJ, Volpes R, Foets B, Missotten L. Distribution of very late activation integrins in the human cornea. An immunohistochemical study using monoclonal antibodies. Invest Ophthalmol Vis Sci 1991;32:2079-85.

34. Kelsh-Lasher RM, Ambesi A, Bertram C, McKeown-Longo PJ. Integrin alpha4betal and TLR4 Cooperate to Induce Fibrotic Gene Expression in Response to Fibronectin's EDA Domain. J Invest Dermatol 2017;137:2505-12. [CrossRef]

35. Ferrari G, Bignami F, Rama P. Tumor necrosis factor- $\alpha$ inhibitors as a treatment of corneal hemangiogenesis and lymphangiogenesis. Eye Contact Lens 2015;41:72-6. [CrossRef]

36. Vanderslice P, Munsch CL, Rachal E, Erichsen D, Sughrue KM, Truong AN, et al. Angiogenesis induced by tumor necrosis factor-agr; is mediated by alpha4 integrins. Angiogenesis 1998;2:265-75. [CrossRef]

37. Tonks AJ, Cooper RA, Jones KP, Blair S, Parton J, Tonks A. Honey stimulates inflammatory cytokine production from monocytes. Cytokine 2003;21:242-7. [CrossRef]

38. Tonks A, Cooper RA, Price AJ, Molan PC, Jones KP. Stimulation of TNF-alpha release in monocytes by honey. Cytokine. 200I; |4:240-2. [CrossRef]

39. Kohno K, Okamoto I, Sano O, Arai N, Iwaki K, Ikeda M, et al. Royal jelly inhibits the production of proinflammatory cytokines by activated macrophages. Biosci Biotechnol Biochem 2004;68: I38-45. [CrossRef] 